\title{
TRENDS IN OVERWEIGHT AND OBESITY IN CZECH SCHOOLCHILDREN FROM 1998 TO 2014
}

\author{
Zdeněk Hamřík', Dagmar Sigmundová2, Jan Pavelka², Michal Kalman², Erik Sigmund² \\ ${ }^{1}$ Department of Recreation and Leisure Studies, Faculty of Physical Culture, Palacký University Olomouc, Olomouc, Czech Republic \\ ${ }^{2}$ Institute of Active Lifestyle, Faculty of Physical Culture, Palacký University Olomouc, Olomouc, Czech Republic
}

\begin{abstract}
SUMMARY
Objective: Overweight and obesity in adolescents is associated with many health risks and considerable direct and indirect healthcare costs. The purpose of this study is to examine trends in the prevalence of overweight and obesity in 11-, 13- and 15-year-old adolescents in the Czech Republic from 1998 to 2014.

Methods: Data from five self-reported survey rounds (1998, 2002, 2006, 2010, and 2014) of the Health Behaviour in School-aged Children Study (HBSC) were used to assess trends in overweight and obesity among Czech adolescents. The total sample consisted of 19,103 adolescents (51.2\% girls). A logistic regression analysis was used to assess trends in different age and gender categories.

Results: From 1998 to 2014 a significant increase in the prevalence of overweight and obesity was observed among boys in all age categories (11 years old $22.2 \%_{1998}-28.3 \%_{2014} ; 13$ years old $17.9 \%_{1998}-26.7 \%_{2014} ; 15$ years old $\left.9.8 \%_{1998}-20.8 \%_{2014}\right)$ and among 15 -year-old girls $\left(6.0 \%{ }_{1998}-10.9 \%_{2014}\right.$ ). None of the age and gender categories showed an overall decrease over the 16-year period. In boys, the prevalence of overweight was significantly higher with steeper negative trends compared with girls. However, stabilization in overweight rates was observed between 2010 and 2014 in all age and gender groups.

Conclusion: Nationally representative self-reported data show a significant increase in overweight (including obesity) prevalence among children from 1998 to 2014 in the Czech Republic. The results also suggest stabilization in overweight prevalence between 2010 and 2014 . Continuing research is needed to determine future trends while interventions aimed at reducing overweight and obesity in children should be implemented on different levels of public policy.
\end{abstract}

Key words: adolescents, body mass index, HBSC, time trends, prevalence

Address for correspondence: Z. Hamrík, Faculty of Physical Culture, Palacký University Olomouc, třída Míru 117, 771 11 Olomouc, Czech Republic. E-mail: zdenek.hamrik@upol.cz

https://doi.org/10.21101/cejph.a5099

\section{INTRODUCTION}

Over the past three decades, overweight and obesity in children has been one of the main public health issues in many countries worldwide (1-3). Child overweight (including obesity) has numerous consequences for physical, mental and social health in children and adolescents $(4,5)$. Moreover, obese children are more likely to remain obese in adulthood since around $80 \%$ of obese adolescents will still be obese in adulthood (6). Childhood obesity also determines healthcare costs occurring in adulthood; therefore, reducing child obesity could have a substantial impact on reducing future health care costs (7). Trends in the prevalence of childhood overweight and obesity represent an important health indicator used in various national policies aiming at overweight and obesity prevention and reduction.

Globally, the proportion of children and adolescents with overweight and obesity increased substantially from 1980 in both developed and developing countries (8). Increasing prevalence of overweight in children has also been reported in many Eastern European countries since 2002 (9). Additionally, rising trends in the prevalence of more severe forms of obesity were reported in Australia or the United States $(10,11)$. Moreover, no national success stories have been reported in the past 33 years in terms of reducing obesity and the probability of meeting the global obesity target is virtually zero (12).

On the other hand, van Jaarsveld and Gulliford (13), who used primary care electronic health records in England, reported stabilization in the prevalence of overweight and obesity in children between 2004 and 2013 in the UK. Another study by Keane et al. (14) also suggested that overweight and obesity in the Republic of Ireland reached a plateau and may start to fall. Stabilization of obesity rates in schoolchildren was also observed in urban Sweden (15). In contrary to this, a current literature review by Visscher et al. (16) concluded that the recent break in the obesity epidemic needs to be interpreted with caution and that the public health issue of obesity is still increasing.

In the Czech Republic, only few long-term studies dealing with child and adolescent overweight and obesity were published. Kunešová et al. (17) report an increasing prevalence of overweight and obesity in 7-year-old Czech children since 1951 and adds that since 2001 prevalence has plateaued with the exception of boys. Another study aimed at preschool children also confirmed an insignificant increase in the obesity level between 2005 and 2015 (18). An increasing percentage 
of obesity or overweight was reported between 2002 and 2014 in adolescents $(19,20)$.

The objective of the current study is to analyse trends in the prevalence of overweight and obesity in 11-, 13- and 15-year-old adolescents in the Czech Republic by gender and age groups between 1998 and 2014. Self-reported data from five survey cycles $(1998,2002,2006,2010$, and 2014) of the Health Behaviour in School-aged Children Study were used.

\section{MATERIALS AND METHODS}

The present study follows the standardized international HBSC research protocol (21). The HBSC study is a WHO collaborative cross-sectional school-based study focusing on health and health behaviour of school-aged children. The study was conducted in the Czech Republic from 1998 to 2014 in 4-year cycles. Each survey round was approved by the Ethical Committee of the Faculty of Physical Culture or the National Institute of Public Health and followed all ethical and legal requirements for this type of study in each survey round. Completion of the HBSC questionnaire by children was voluntary and anonymity and confidentiality were ensured. No incentives were provided in return for participation. Data cleaning was performed by the International Databank, University of Bergen, Norway, in compliance with the international HBSC standards (22).

\section{Sample}

Self-reported HBSC data from the Czech Republic collected during April, May and June from 1998 to 2014 were analysed. The response rate varied from $87.0 \%$ in 2010 to $89.8 \%$ in 1998 . Finally, data from 23,740 pupils were obtained. As a result of some unlikely responses and missing values in childrens' weight and height, 713 questionnaires were excluded from the analysis. Furthermore, according to the HBSC-protocol only 11-, 13- and 15 -year-old adolescents were selected for the analysis. The age category of 11 years included children aged $11.0-11.99$ years, the age category of 13 years included children aged 13.0-13.99 years and children aged 15.0-15.99 years were regarded as the age category of 15 years old. The final sample consisted of 19,103 (51.2\% of girls) adolescents aged 11,13 and 15 years (Table 1$)$.

\section{Survey Items}

\section{Weight Status}

In the present study, data on body height and weight were obtained via a self-report questionnaire with an accuracy of 0.5 $\mathrm{cm}$ and $0.1 \mathrm{~kg}$. Body mass index (BMI) $\left(\mathrm{kg} / \mathrm{m}^{2}\right)$ was calculated as body weight ( $\mathrm{kg}$ ) divided by body height $(\mathrm{m})$ squared. Sex- and age-specific cut-off values for weight status based on the World Health Organization percentile BMI charts for 5- to 19-year-old children were used to classify obese, overweight and normal body mass (23). Overweight and obesity were represented by $85-97 \%$ and $>97 \%$, respectively, on age-differentiated BMI charts (23). Chronological age of adolescents used to compute age-differentiated BMI was calculated as the difference between the date of application of the HBSC questionnaire and the selfreported month and year of the respondent's birth.

\section{Statistical Analyses}

All data were analysed using IBM SPSS (Version 22). First of all, the composition of the sample, age and gender categories according to each survey round were described. To determine the trends, a logistic regression analysis (Enter method) was used with a dependent variable - overweight and obesity and an independent categorical variable, which was the year that the survey was completed, i.e. $1998,2002,2006,2010$, or 2014. To describe the differences in overweight and obesity by gender and age categories in more detail, the Analysis of Variance approach was applied with a dependent variable - overweight and obesity and independent variables of gender (boys, girls) and age categories (11-, 13- and 15-year old). The Levene's test to assess the equality of variances for an average in BMI was used and the t-test for equality of means was used to assess the statistical significance in average BMI with increasing age between 1998 and 2014.

\section{RESULTS}

Table 2 presents the proportions of school-aged overweight children by age and gender. The trends over the 1998-2014 period were, however, generally similar for adolescents of all ages. From 1998 to 2014 a significant increase in the prevalence of overweight

Table 1. Descriptive characteristics of the samples, HBSC study, Czech Republic 1998-2014 $(N=19,103)$

\begin{tabular}{|c|c|c|c|c|c|c|c|c|c|c|c|c|}
\hline & \multicolumn{6}{|c|}{ Boys $(n=9,317)$} & \multicolumn{6}{|c|}{ Girls $(n=9,786)$} \\
\hline & \multicolumn{6}{|c|}{ Age } & \multicolumn{6}{|c|}{ Age } \\
\hline & \multicolumn{2}{|c|}{11} & \multicolumn{2}{|c|}{13} & \multicolumn{2}{|c|}{15} & \multicolumn{2}{|c|}{11} & \multicolumn{2}{|c|}{13} & \multicolumn{2}{|c|}{15} \\
\hline & $\mathrm{n}$ & $\%$ & $\mathrm{n}$ & $\%$ & $\mathrm{n}$ & $\%$ & $\mathrm{n}$ & $\%$ & $\mathrm{n}$ & $\%$ & $\mathrm{n}$ & $\%$ \\
\hline \multicolumn{13}{|l|}{ Survey year } \\
\hline $1998(n=2,979)$ & 477 & 32.6 & 515 & 35.2 & 471 & 32.2 & 510 & 33.6 & 524 & 34.6 & 482 & 31.8 \\
\hline $2002(n=4,045)$ & 656 & 34.3 & 610 & 32.0 & 643 & 33.7 & 715 & 33.5 & 720 & 33.7 & 701 & 32.8 \\
\hline $2006(n=4,124)$ & 672 & 32.1 & 702 & 33.5 & 720 & 34.4 & 651 & 32.1 & 680 & 33.5 & 699 & 34.4 \\
\hline $2010(n=3,833)$ & 622 & 33.9 & 573 & 31.2 & 642 & 34.9 & 610 & 30.6 & 702 & 35.2 & 684 & 34.2 \\
\hline $2014(n=4,122)$ & 607 & 30.1 & 682 & 33.9 & 725 & 36.0 & 650 & 30.8 & 737 & 35.0 & 721 & 34.2 \\
\hline Total $(N=19,103)$ & 3,034 & 32.6 & 3,082 & 33.1 & 3,201 & 34.3 & 3,136 & 32.0 & 3,363 & 34.4 & 3,287 & 33.6 \\
\hline
\end{tabular}


Table 2. Trends in the prevalence of overweight and obesity, HBSC study, Czech Republic 1998-2014

\begin{tabular}{|c|c|c|c|c|c|c|c|c|}
\hline \multirow{3}{*}{ Variable } & \multirow{3}{*}{$\begin{array}{c}1998 \\
\%\end{array}$} & \multirow{3}{*}{$\begin{array}{c}2002 \\
\%\end{array}$} & \multirow{3}{*}{$\begin{array}{c}2006 \\
\%\end{array}$} & \multirow{3}{*}{$\begin{array}{c}2010 \\
\%\end{array}$} & \multirow{3}{*}{$\begin{array}{c}2014 \\
\%\end{array}$} & \multicolumn{3}{|c|}{2014 vs. 1998} \\
\hline & & & & & & \multirow{2}{*}{$\mathrm{OR}$} & \multicolumn{2}{|c|}{$\mathrm{Cl}$} \\
\hline & & & & & & & Lower & Upper \\
\hline \multicolumn{9}{|l|}{ Boys } \\
\hline $11-11.99$ years & 22.2 & 23.2 & 29.9 & 30.2 & 28.3 & $1.38^{*}$ & 1.05 & 1.83 \\
\hline $13-13.99$ years & 17.9 & 17.0 & 20.8 & 26.9 & 26.7 & $1.67^{* * *}$ & 1.26 & 2.22 \\
\hline $15-15.99$ years & 9.8 & 16.0 & 16.7 & 20.4 & 20.8 & $2.43^{* * *}$ & 1.71 & 3.46 \\
\hline \multicolumn{9}{|l|}{ Girls } \\
\hline $11-11.99$ years & 11.4 & 10.1 & 22.1 & 14.4 & 13.5 & 1.22 & 0.86 & 1.74 \\
\hline $13-13.99$ years & 8.4 & 9.2 & 15.0 & 10.3 & 11.1 & 1.37 & 0.93 & 2.01 \\
\hline $15-15.99$ years & 6.0 & 6.6 & 11.9 & 10.5 & 10.8 & $1.86^{* *}$ & 1.22 & 2.95 \\
\hline
\end{tabular}

Results of logistic regression; \% percentage of participants who are overweight or obese; OR: odds ratio (cohorts from 1998 are reference groups); Cl: $95 \%$ confidence interval; ${ }^{*} p \leq 0.05 ;{ }^{* *} p \leq 0.01 ;{ }^{* * *} p \leq 0.001$

and obesity was observed among boys in all age categories (11 years old $22.2 \%_{1998}-28.3 \%_{2014} ; 13$ years old $17.9 \%_{1998}-26.7 \%_{2014}$; 15 years old $9.8 \%_{1998}-20.8 \%{ }_{2014}$ ) and among 15 -year-old girls $\left(6.0 \%_{1998}-10.9 \%_{2014}\right)$. None of the age and gender categories showed an overall decrease over the 16-year period. In boys, the prevalence of overweight was significantly higher with steeper negative trends compared with girls. However, stabilization in overweight rates was observed between 2010 and 2014 in all age and gender groups.

Differences in weight by survey year in boys and girls are displayed in Figures 1 and 2. In boys, the proportion of obese individuals significantly increased from 1998 to 2014 in the age category of 11 -year olds from 6.3 to $9.9 \%(\mathrm{p} \leq 0.05)$ and 15 -year olds from 0.8 to $5.0 \%(\mathrm{p} \leq 0.001)$. In girls, the proportion of obese individuals changed significantly only in 15 -year olds from 1.0 to $3.7 \%(\mathrm{p} \leq 0.05)$ between 1998 and 2014.

Changes in average BMI values in boys and girls in different age categories from 1998 to 2014 are shown in Figures 3 and 4.
A clear significant negative trend can be seen in 15-year-old boys and girls. In boys, an average BMI increase from 20.2 in 1998 to 21.1 in 2014 ( $\mathrm{p} \leq 0.001)$ was observed, while in girls, an average BMI increase was from 20.1 in 1998 to 20.5 in 2014 ( $\mathrm{p} \leq 0.05$ ). A significant negative trend was also observed in 13-year-old boys (increase from 19.0 in 1998 to 19.7 in 2014; $\mathrm{p} \leq 0.001$ ). Changes in average BMI over time in other age and gender groups were not significant.

\section{DISCUSSION}

The present study investigated trends in the prevalence of overweight and obesity in 11-, 13- and 15-year-old adolescents in the Czech Republic from 1998 to 2014. The study revealed a significant increase in the prevalence of overweight (including obesity) in Czech boys in all age categories and in girls at the age of 15 . However, the results also imply stabilization in

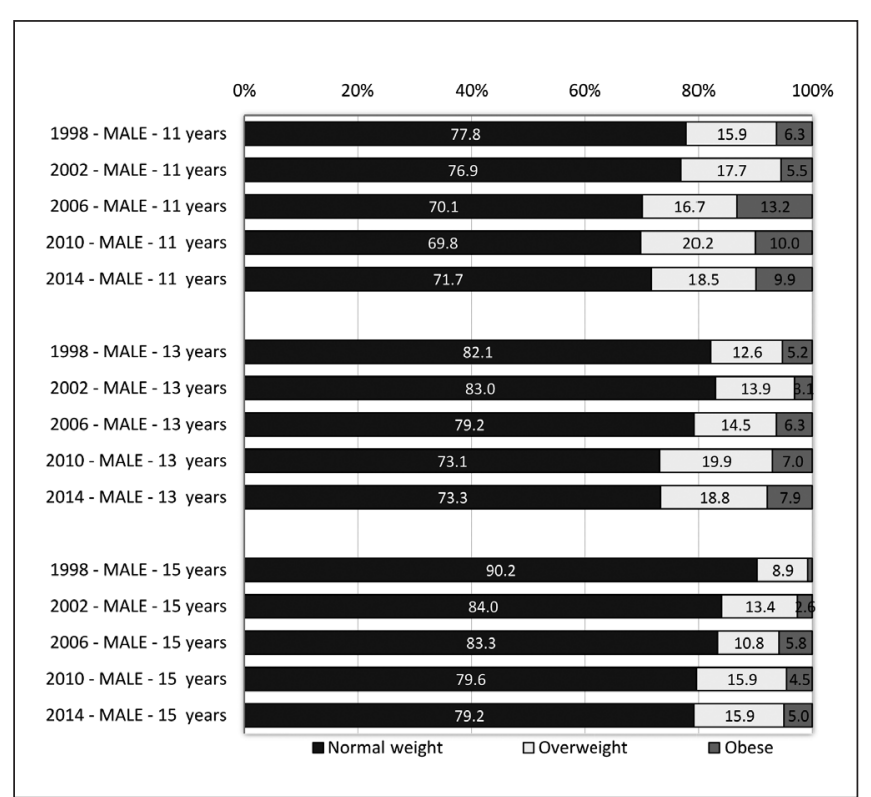

Fig. 1. Proportions of 11-, 13- and 15-year-old boys displaying different weight status by year of survey.

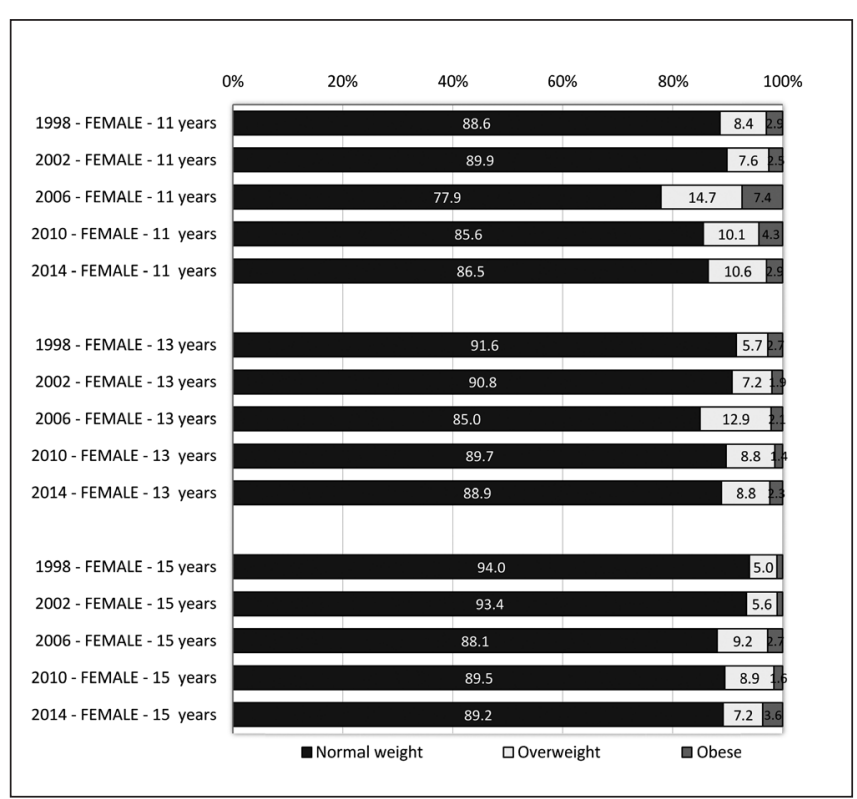

Fig. 2. Proportions of 11-, 13- and 15-year-old girls displaying different weight status by year of survey. 


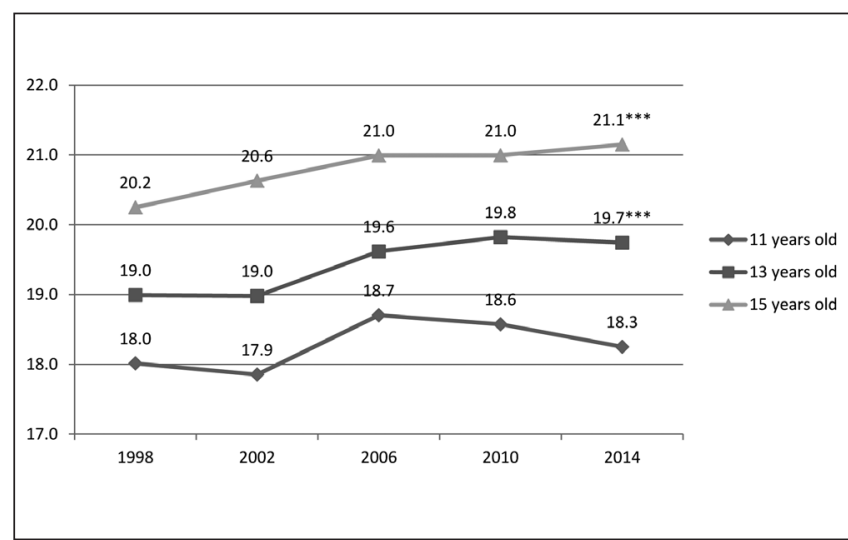

Fig. 3. Average BMI values among boys, 1998-2014. Results of t-test for equality of means between 1998 and 2014; ${ }^{* \star *} p \leq 0.001$

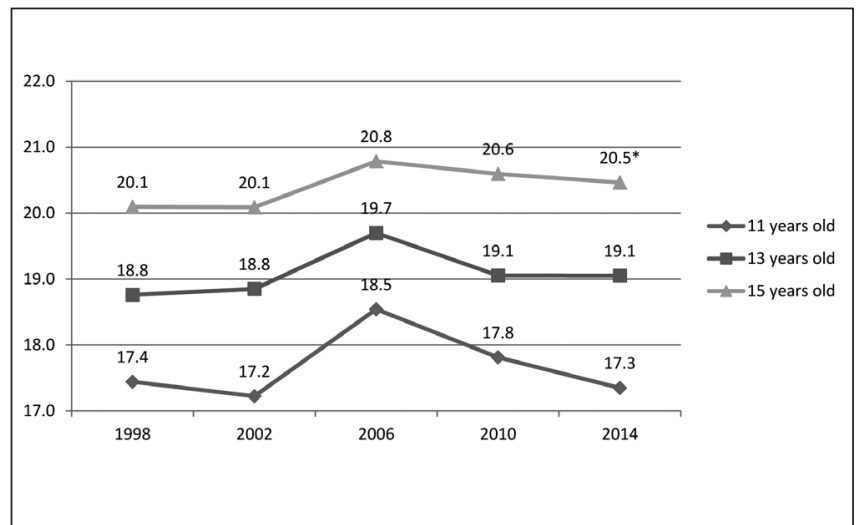

Fig. 4. Average BMI values among girls between 1998-2014. Results of t-test for equality of means between 1998 and 2014; ${ }^{p} \mathrm{p} \leq 0.05$

overweight rates between 2010 and 2014 in all age and gender groups. The present study extends the results of our previously published studies $(19,20)$ and is in line with international results demonstrating stabilization of overweight in the same age groups in boys and girls $(9,24)$.

Stabilization in BMI was also confirmed in different age categories in school-aged children in the Czech Republic (19, $20)$ as well as internationally in different countries across the globe (25-27).

On the other hand, Skinner et. al. (28), who focuses on obesity in the US, point out that despite substantial clinical and policy efforts targeting the issue of overweight and obesity in children, there is no evidence of a positive change in obesity prevalence in any age group. A current review of literature by Visscher et al. (16) also concludes that trend data based on waist circumference suggest an overall increase and the public health problem of obesity is still increasing. In addition, other studies highlight that the prevalence of overweight and obesity in children remains high and should be highlighted as an important public health issue $(12,28)$.

\section{Strength and Limitations}

The present study has several strength and limitations. Firstly, the investigation only included available representative data from the Czech Republic concerning young adolescents from 1998 to
2014. With the respect to all requirements of the standardized HBSC study protocol (21), the same methodology was used in all survey rounds. However, the authors of the present study used self-reported data of weight and height, which might lead to underestimation of the results, especially in girls (29). In contrast to this, the trend analysis was based on the same methodology approach, thus the underestimation of the results of the present study is not likely to influence the overall picture of the study. In studies assessing BMI in children, high numbers of missing values might also lead to incorrect conclusions. However, the excellent response rate in the Czech Republic ( $>87.0 \%$ in all survey rounds) eliminates this constraint. Lastly, overweight and obesity were calculated on age-differentiated BMI charts according to the WHO standards (23). Using different standards to classify child overweight and obesity might lead to slightly different findings but should not influence the trends.

\section{CONCLUSIONS}

Czech nationally representative self-reported data from the Health Behaviour in School-aged Children Study show a significant increase in overweight (including obesity) prevalence among children from 1998 to 2014 with signs of stabilization in overweight prevalence between 2010 and 2014. Further research is needed to assess future trends in the prevalence of child overweight in the Czech Republic as well as interventions to decrease the proportion of overweight and obese children. Czech national health promoting strategies and policies such as the Czech National Strategy for Health Protection and Promotion and Disease Prevention - Health 2020 should be accompanied and supported by actions at national, regional and municipal level and should be linked to the budget of key stakeholders in this area.

\section{Acknowledgement}

This work was supported by the research grant of the Czech Science Foundation Reg. No. 17-12579S and by the Czech Ministry of Education, Youth and Sports (MEYS) under Contract No. LG 14043.

\section{Conflict of Interests}

None declared

\section{REFERENCES}

1. World Health Organization. Obesity: preventing and managing the global epidemic: report of a WHO Consultation on Obesity. Geneva: WHO; 1998.

2. Ebbeling CB, Pawlak DB, Ludwig DS. Childhood obesity: public-health crisis, common sense cure. Lancet. 2002 Aug 10;360(9331):473-82.

3. Lobstein T, Jackson-Leach R, Moodie ML, Hall KD, Gortmaker SL, Swinburn BA, et al. Child and adolescent obesity: part of a bigger picture. Lancet. 2015 Jun 20;385(9986):2510-20.

4. Reilly JJ, Methven E, McDowell ZC, Hacking B, Alexander D, Stewart L, et al. Health consequences of obesity. Arch Dis Child. 2003 Sep;88(9):748-52.

5. Sanders RH, Han A, Baker JS, Cobley S. Childhood obesity and its physical and psychological co-morbidities: a systematic review of Australian children and adolescents. Eur J Pediatr. 2015 Jun;174(6):715-46.

6. Simmonds M, Llewellyn A, Owen CG, Woolacott N. Predicting adult obesity from childhood obesity: a systematic review and meta-analysis. Obes Rev. 2016 Feb;17(2):95-107. 
7. Sonntag D, Ali S, Lehnert T, Konnopka A, Riedel-Heller S, König HH. Estimating the lifetime cost of childhood obesity in Germany: results of a Markov Model. Pediatr Obes. 2015 Dec;10(6):416-22.

8. Ng M, Fleming T, Robinson M, Thomson B, Graetz N, Margono C, et al. Global, regional, and national prevalence of overweight and obesity in children and adults during 1980-2013: a systematic analysis for the Global Burden of Disease Study 2013. Lancet. 2014 Aug 30;384(9945):766-81.

9. Ahluwalia N, Dalmasso P, Rasmussen M, Lipsky L, Currie C, Haug E, et al. Trends in overweight prevalence among 11-, 13- and 15-year-olds in 25 countries in Europe, Canada and USA from 2002 to 2010. Eur J Public Health. 2015 Apr;25 Suppl 2:28-32.

10. Garnett SP, Baur LA, Jones AM, Hardy LL. Trends in the prevalence of morbid and severe obesity in Australian children aged 7-15 years, 19852012. PLoS One. 2016 May 12;11(5):e0154879. doi: 10.1371/journal. pone.0154879. eCollection 2016.

11. Skinner AC, Perrin EM, Skelton JA. Prevalence of obesity and severe obesity in US children, 1999-2014. Obesity (Silver Spring). 2016 May;24(5):1116-23.

12. NCD Risk Factor Collaboration (NCD-RisC). Trends in adult body-mass index in 200 countries from 1975 to 2014: a pooled analysis of 1698 population-based measurement studies with $19 \cdot 2$ million participants. Lancet. 2016 Apr 2;387(10026):1377-96.

13. van Jaarsveld $\mathrm{CH}$, Gulliford MC. Childhood obesity trends from primary care electronic health records in England between 1994 and 2013: population-based cohort study. Arch Dis Child. 2015 Mar;100(3):214-9.

14. Keane E, Kearney PM, Perry IJ, Kelleher CC, Harrington JM. Trends and prevalence of overweight and obesity in primary school aged children in the Republic of Ireland from 2002-2012: a systematic review. BMC Public Health. 2014 Oct 14;14:974. doi: 10.1186/1471-2458-14-974.

15. Lissner L, Sohlström A, Sundblom E, Sjöberg A. Trends in overweight and obesity in Swedish schoolchildren 1999-2005: has the epidemic reached a plateau? Obes Rev. 2010 Aug;11(8):553-9.

16. Visscher TL, Heitmann BL, Rissanen A, Lahti-Koski M, Lissner L. A break in the obesity epidemic? Explained by biases or misinterpretation of the data? Int J Obes (Lond). 2015 Feb;39(2):189-98.

17. Kunešová M, Vignerová J, Pařizková J, Procházka B, Braunerová R, Riedlová $\mathrm{J}$, et al. Long-term changes in prevalence of overweight and obesity in Czech 7-year-old children: evaluation of different cut-off criteria of childhood obesity. Obes Rev. 2011 Jul;12(7):483-91.

18. Sigmund E, Sigmundová D, Badura P, Trhlíková L, Madarasová Gecková A. Time trends: a ten-year comparison (2005-2015) of pedometer-determined physical activity and obesity in Czech preschool children. BMC Public Health. 2016 Jul 13;16:560. doi: 10.1186/s12889-016-3269-5.
19. Sigmund E, Sigmundová D, Badura P, Kalman M, Hamrik Z, Pavelka J. Temporal trends in overweight and obesity, physical activity and screen time among Czech adolescents from 2002 to 2014: A National Health Behaviour in School-Aged Children Study. Int J Environ Res Public Health. 2015 Sep 18;12(9):11848-68.

20. Sigmundová D, Sigmund E, Hamrik Z, Kalman M. Trends of overweight and obesity, physical activity and sedentary behaviour in Czech schoolchildren: HBSC study. Eur J Public Health. 2014 Apr;24(2):210-5.

21. Currie C, Gabhainn SN, Godeau E; International HBSC Network Coordinating Committee. The Health Behaviour in School-aged Children: WHO Collaborative Cross-National (HBSC) study: origins, concept, history and development 1982-2008. Int J Public Health. 2009 Sep;54 Suppl 2:131-9.

22. Roberts C, Freeman J, Samdal O, Schnohr CW, de Looze ME, Gabhainn $\mathrm{SN}$, et al.; International HBSC Study Group. The Health Behaviour in School-aged Children (HBSC) study: methodological developments and current tensions. Int J Public Health. 2009 Sep;54 Suppl 2:140-50.

23. World Health Organization. Growth reference data for 5-19 years. Geneva: WHO; 2007.

24. Olds T, Maher C, Zumin S, Péneau S, Lioret S, Castetbon K, et al. Evidence that the prevalence of childhood overweight is plateauing: data from nine countries. Int J Pediatr Obes. 2011 Oct;6(5-6):342-60.

25. Pan L, Grummer-Strawn LM, McGuire LC, Park S, Blanck HM. Trends in state/territorial obesity prevalence by race/ethnicity among U.S. lowincome, preschool-aged children. Pediatr Obes. 2016 Oct;11(5):397-402.

26. van Jaarsveld $\mathrm{CH}$, Gulliford MC. Childhood obesity trends from primary care electronic health records in England between 1994 and 2013: population-based cohort study. Arch Dis Child. 2015 Mar;100(3):214-9.

27. Xiao Y, Qiao Y, Pan L, Liu J, Zhang T, Li N, et al. Trends in the prevalence of overweight and obesity among Chinese preschool children from 2006 to 2014. PLoS One. 2015 Aug 12;10(8):e0134466. doi: 10.1371/journal. pone. 0134466 .

28. Skinner AC, Perrin EM, Skelton JA. Prevalence of obesity and severe obesity in US children, 1999-2014. Obesity (Silver Spring). 2016 May;24(5):1116-23.

29. Elgar FJ, Stewart JM. Validity of self-report screening for overweight and obesity. Evidence from the Canadian Community Health Survey. Can J Public Health. 2008 Sep-Oct;99(5):423-7.

Received March 9, 2017 Accepted June 13, 2017 